\title{
Resiliència i estrès demogràfic a la Catalunya del segle XXI
}

\section{Andreu Domingo, Centre d'Estudis Demogràfics}

Si la resiliència és definida com la capacitat d'un individu o d'un sistema complex de tornar a l'antic equilibri o trobar-ne un de nou després d'una situació crítica, sens dubte podem caracteritzar la demografia catalana del segle XXI com un sistema resilient.

En el nou mil-lenni, Catalunya ha donat el salt dels 6,2 als 7,5 milions gràcies fonamentalment al boom migratori, amb més d'1,7 milions de persones arribades de 2000 a 2014. En conseqüència, el 17\% de la població empadronada al 2015 havia nascut a l'estranger. A partir de 2008, a causa de l'esclat de la bombolla immobiliària i financera primer, i dels ajustos estructurals més tard, l'arribada de fluxos internacionals ha caigut a la meitat, alhora que s'ha incrementat l'emigració, gairebé 800 mil sortides, de les que només un 14\% han estat protagonitzades per autòctons. I, amb tot, les pèrdues poblacionals han estat mínimes. La formació de les famílies i la fecunditat es fan ressò d’aquesta immigració recent i de l’impacte de la crisi, però també acusen la frustració d'un projecte igualitari de gènere encara no acomplert, disminuint el nombre d'unions i de naixements, i accelerant el procés de desinstitucionalització endegat fa dècades. Mentrestant, l'esperança de vida en néixer ha seguit creixent, guanyant des de 2000 uns anys, escurçant distàncies entre els sexes, igualant-se en la fortuna i en la desgràcia.

FIGURA 1. Població, creixement vegetatiu i saldo migratori, a Catalunya, 1965-2015

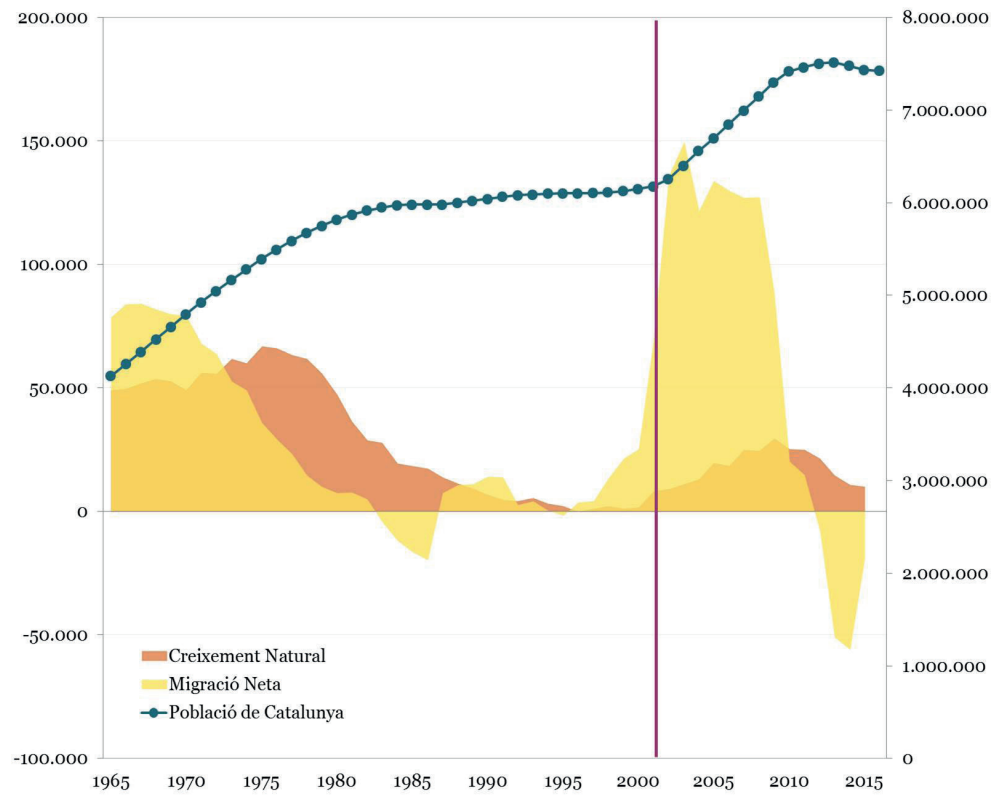

Font: Estimacions de població a partir de Censos i Padrons (INE): 1965-1983 (CED) i 1984-2015 (Idescat; Naixements i Defuncions, 1965-2014 (Idescat).

\section{EL CREIXEMENT: L'EXCEPCIONAL COM} A NORMA

Durant el segle XXI Catalunya ha enregistrat un creixement poblacional de l'11,8 per mil, el que li ha permès mantenir la seva quota mundial: 1,01 de cada mil habitants del planeta segueix vivint a Catalunya al 2014. Només en un any, el 2002, la població va créixer per sobre de les 160 mil persones, després de vint anys d'estancament i ben per damunt els increments experimentats als seixanta. Aquest cop, però, el 93\% de l'augment corresponia al saldo migratori, mentre que mig segle abans només en depenia en el 60\% (Figura 1). A partir de 2008, amb la crisi econòmica, el creixement comença a davallar ràpidament a conseqüència del saldo migratori. La pèrdua de població podria haver tocat fons el 2013, amb una minva d'unes 45 mil persones, de la que majoritàriament n'és responsable el saldo migratori negatiu, atès que degut a l'estructura envellida de la població el nombre de defuncions tendeixi a l'alça, al voltant de 61 mil, a penes compensades pels poc més de 71 mil naixements enregistrats. 
Rere aquesta evolució doncs, hi ha la progressió de la immigració que, com sabem, ja fa més d'un segle ha esdevingut el pal de paller de la demografia a Catalunya (Cabré, 1999). Així, malgrat el canvi en el signe del saldo migratori i el feble creixement vegetatiu, la població a 1 de gener de 2015 s'estimava en els 7,4 milions de persones.

Catalunya, com la majoria de societats post-transicionals, ha esdevingut un Sistema Complex de Reproducció basat en l'aportació migratòria. La immigració empesa pel cicle econòmic, ha deixat petja en tots i cadascun dels fenòmens demogràfics del segle XXI. El ritme espasmòdic de les migracions, cada cop més intens, de longitud més elevada i amplitud més curta i oscilllatori en la direcció, imposa l'excepcionalitat com a norma.

\section{FORMACIÓ DE PARELLA I FECUNDITAT: UN PROJECTE D'IGUALACIÓ INCOMPLERT}

El creuament entre la conjuntura econòmica i el procés d'igualació per raó de gènere, constitueix l'horitzó en el que s'ha mogut l'evolució recent de la formació de la família -que comprèn les seves formes d'unió i dissolució-, i la fecunditat. Canvis que vénen de lluny, dels que en podríem trobar les arrels als anys setanta.

Des de 1999 els matrimonis s'han reduït en un 19\% (de 32 mil a 26 mil) i han canviat la seva forma: 83\% dels 26 mil enregistrats el 2014 eren civils, mentre que a finals del segle XX només ho eren una tercera part. La immigració (el 26\% dels matrimonis impliquen com a mínim una persona de nacionalitat estrangera), però també les segones núpcies, en són responsables. L'edat mitjana al primer matrimoni dels contraents s'ha allargat en 4,5 anys (34,3 anys pels homes i 32,3 per les dones) i gairebé la meitat de les parelles entre 25 i els 34 anys cohabiten. El 2014, el 47\% dels fills eren nascuts fora del matrimoni, producte de la cohabitació majoritàriament. El nombre de ruptures (nul·litats, separacions i divorcis), durant aquest període ha crescut lleugerament (de 19.085 a 19.591), després d'haver tocat sostre el 2006 amb 27.846 trencaments, a causa de la supressió de la necessitat de passar un temps de separació prèvia al divorci (Solsona, et. al., 2014).

El nombre de naixements va augmentar dels 59.616 al 1999 fins als 89 mil al 2008 per la combinació de tres fenòmens: una recuperació de la fecunditat (de l'1,21 fills per dona va arribar a 1,53); una estructura per edats més favorable en les dones catalanes; i, l'aportació per part de les dones estrangeres (Figura 2). Tot i que al 2014 els 1,39 fills per dona superen encara l'1,15 que és el nivell més baix assolit l'any 1995, ens seguim movent en la banda baixa de la fecunditat mundial. L'aportació de les estrangeres s'ha d'entendre més des de la complementarietat dels calendaris que no pas per un nombre major de fills: sempre per sota dels dos fills per dona. Si les autòctones es caracteritzen per un calendari tardà, amb una edat mitjana a la maternitat al voltant dels 32 anys durant el període, el conjunt de les estrangeres ha oscil-lat entre els 28 i els 29,6 anys. Entre 2000 i 2013, el 26,6\% dels naixements enregistrats tenien pare o mare nascut a l'estranger. Un cop arribada la crisi, els naixements i la fecunditat han davallat tant entre les autòctones com entre les immigrades, adaptant-se a les restriccions econòmiques, però també degut a la progressiva disminució de potencials mares (per la pròpia estructura en el cas de les autòctones, per la disminució de la immigració, a més del retorn i la reemigració en el de les immigrades).

FIGURA 2. Índex Sintètic de Fecunditat (ISF) i Edat Mitjana a la Maternitat (EMM), per nacionalitat (espanyola o estrangera), Catalunya, 1975-2014

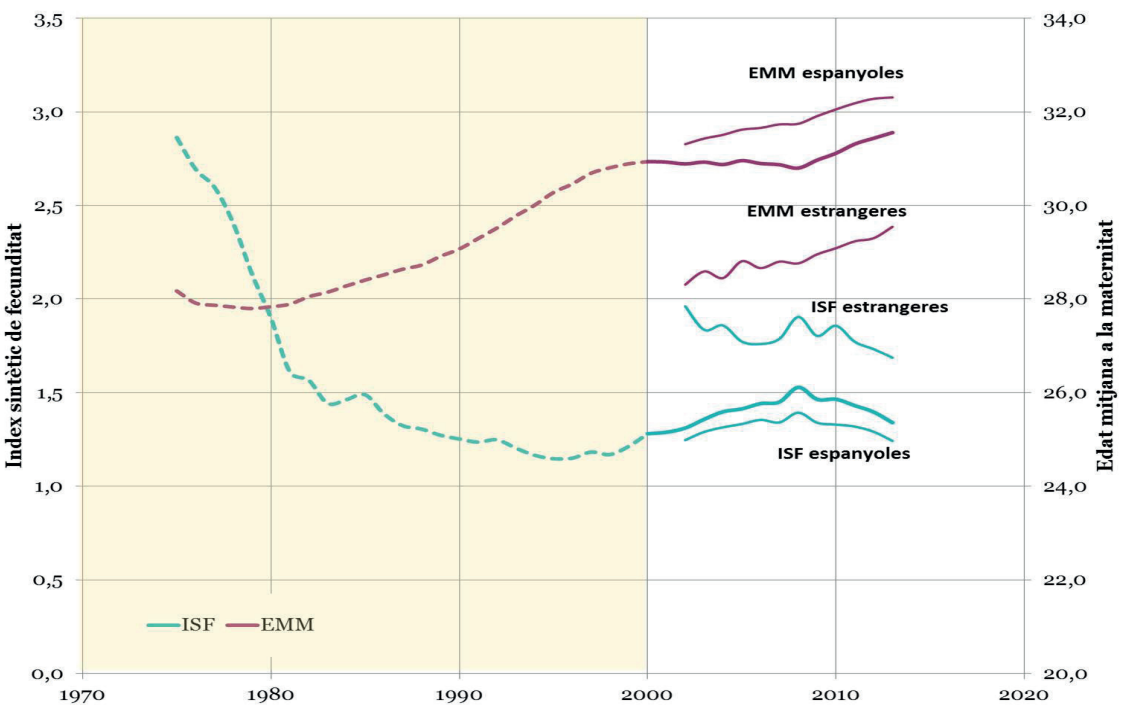

Font: Elaboració CED, Indicadores Demográficos, INE

La baixa fecunditat a Catalunya es deu bàsicament a la creixent infecunditat (el nombre de dones que en acabar el seu període reproductiu no té fills), i aquesta al seu torn està provocada per l'extraordinari retard a l'edat en tenir el primer fill.

La infecunditat ja se situava al 2007 al voltant del 23\% de les dones, essent un nivell molt alt, tant sols sobrepassat aleshores a Europa per Alemanya o Suïssa (Devolder, 2010). En només dues dècades, de 1991 a 2011, segons dades censals, la infecunditat entre els grups de 30 a 34 anys (on recordem es troba la mitjana d'edat a la maternitat) i dels 34 a 49 anys, s'ha duplicat, passant en el primer cas 
de ser del 24,1\% al 49,7\% i, en el segon, del 14,3\% al 30,5\%. Les raons cal cercar-les en un projecte d'igualació sempre pendent, en un context de desregularització econòmica i de desmantellament de l'Estat del Benestar (Esteve et al., 2016).

\section{LONGEVITAT: EN LA SALUT I EN LA MALALTIA}

El creixement i la lenta però progressiva convergència entre els nivells de l'esperança de vida d'homes i dones han estat els trets més destacables en l'evolució de la longevitat, marcant les pautes de la mortalitat.

Amb 80,4 anys d'esperança de vida al néixer per als homes i 85,9 per a les dones, l'any 2014, Catalunya se situava en la part més alta de l'esperança de vida dels països del món. Els guanys es concentren cada cop més a les darreres edats, essent la millora en la salut a partir dels seixanta cinc anys el component que més fa créixer l'esperança de vida (Blanes Llorens i Spikjer, 2009). El mateix any 2014 s'estimava que els homes de 65 anys viurien encara 19 anys més, mentre que les dones podien afegir 23,1 anys de vida. De seguir amb el ritme de creixement enregistrat des de l'any 2000, per cada any viscut s'afegeix 0,2 anys més de vida a partir dels 65 anys. Això ha estat, sens dubte, resultat tant de l'eficiència creixent del sistema sanitari com de canvis en determinats hàbits de la població

FIGURA 3. Piràmides de la població de Catalunya, per naturalesa, 2000 i 2015

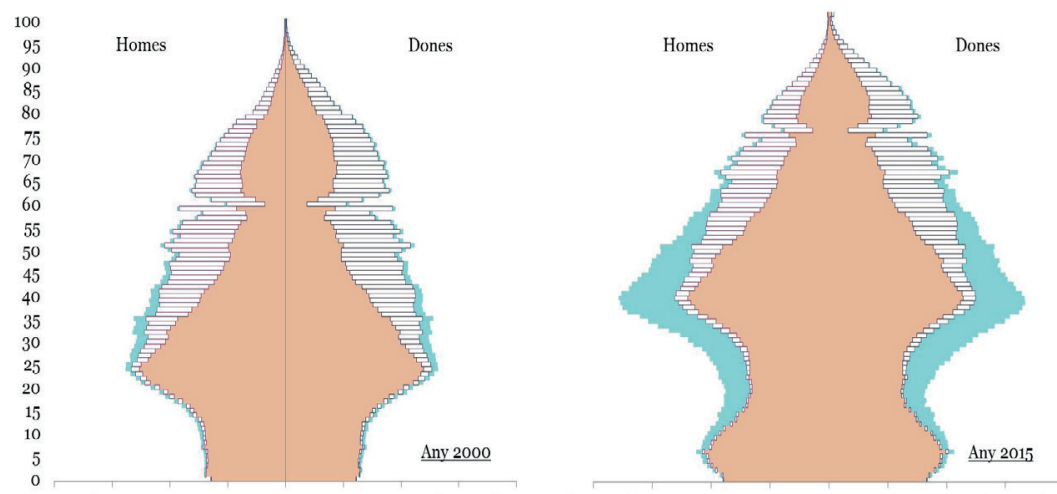

$80.00060 .00040 .00020 .000 \quad 0 \quad 20.00040 .00060 .00080 .000 \quad 80.00060 .00040 .00020 .000 \quad 0 \quad 20.00040 .00060 .00080 .000$

" Nascuts a Catalunya $\square$ Nascuts a la resta d'Espanya $\quad$ "Nascuts a l'estranger

Font: Elaboració CED, Padró Continu de Població 2000 i 2015, INE

La tradicional distància de l'esperança de vida entre homes i dones tendeix a escurçar-se. Aquesta xifra, que al 2000 era de gairebé 7 anys, al 2014 havia disminuït als 5,5, mentre que la diferència d'esperança de vida als seixanta cinc anys s'ha situat al voltant dels 4 . Històricament, l'esmentada diferència reflectia en part un component biològic a favor de la genètica femenina i, en part, un de clarament social, també a favor de les dones que s'abstenien dels hàbits més perjudicials que feien minvar la salut i supervivència dels seus coetanis masculins.

Avui, dins la millora continuada, l'adopció d'hàbits perjudicials per la salut entre les dones -especialment el tabaquisme-, i la correcció entre els homes, els acosta.

\section{MOVIMENTS MIGRATORIS: SOTA EL DIC-}

\section{TAT DEL MERCAT}

La immigració internacional, ho va trastocar tot, o gairebé tot. Tant en la seva pujada, que va provocar un boom els primers anys del segle XXI, com en la seva disminució, amb una caiguda del $51 \%$ des de 2007. Amb tot, la crisi econòmica, malgrat l'èmfasi que s'ha volgut posar en el retorn, no ha significat la interrupció dels fluxos arribats de l'estranger, ja que al darrer any 2014 assoleixen quasi les 100 mil entrades (equivalents a les de l'inici del boom).

El que destaca és el canvi en l'estructura per sexe i edat d'uns fluxos que moltes vegades tradueixen la voluntat de reagrupament familiar i la intensitat segons el lloc d'origen. Així, de forma gairebé desapercebuda, al 2014 sembla que, per algunes nacionalitats, la immigració es troba en un tímid punt d'inflexió. El tema d'actualitat que ens ocupa, és encara un futurible: què succeirà amb uns fluxos de refugiats, que fins el moment han estat quasi inapreciables? En volum, però, l'aportació d'aquest tipus de migracions seguirà essent minoritària.

El llegat més important dels fluxos immigratoris del segle XXI ha estat fins ara les persones que s'han afegit a la població de Catalunya, directa i indirectament a través de la seva descendència. Han transformat el paisatge humà de tots els municipis, petits o grans, però també la composició de la piràmide d'edats (Figura 3).

No han tingut un paper supletori, no han estat migracions de reemplaçament com moltes vegades es pretén, sinó que encara han exagerat més el perfil preexistent afegint-se sobretot a les generacions plenes del baby boom.

En encetar el nou mil·lenni, el percentatge de persones nascudes a l'estranger seguia essent mínim, tot i la seva importància creixent no suposaven més que el $4 \%$, mentre que el percentatge de població nascuda a la resta d'Espanya representava el 27\%, i les persones nascudes a Catalunya el 69\% restant. 
Ara, aquesta distribució es veu completament alterada: els nascuts a l'estranger han passat a representar el 17,0\% dels empadronats, mentre que el pes dels oriünds de la resta d'Espanya ha disminuït fins al 18,3\% i els nascuts a Catalunya fins al 64,7\%. Però també ha variat substancialment la distribució per edats: mentre, com hem vist, la població nascuda a l'estranger es feia present a l'edat activa, els nascuts a la resta d'Espanya, representants de les migracions del segle XX, envellien: el 48,5\% dels nascuts a la resta d'Espanya eren majors de 64 anys.

El segon gran tema, ha estat l'emigració, especialment la de joves autòctons. La borrositat estadística no ha ajudat gaire a la comprensió d'un fenomen nou, polaritzat entre l'expulsió per l'aplicació de mesures d'ajust estructural i la mobilitat pròpia d'una capa emergent de la societat de la informació (Cabré i Domingo, 2014). Malgrat aquest justificat interès, cal reiterar que el gruix de l'emigració entre 2008 i 2014 l'ha representat el retorn i reemigració d'estrangers (el 91,3\% d'aquests moviments amb 709 mil sortides segons les dades de l'Estadística de Migracions de l'INE), mentre que la sortida de persones amb nacionalitat espanyola nascudes a Espanya només abastava el 5,8\% del total, unes 45 mil baixes (incloent-hi els fills d'immigrats nascuts a Espanya i amb nacionalitat espanyola).

\section{CATALUNYA, QUO VADIS?}

Els sacrificis individuals, familiars i col-lectius, han fet possible la resiliència. El preu: persones i generacions que han hagut d'aprendre a fer malabarismes mentre travessaven la corda fluixa per dur a terme els seus projectes vitals, de vegades truncats. No hem d'oblidar que l'impacte de l'evolució econòmica sobre les trajectòries vitals implica una creixent redundància: no tots se'n surten.

Referències bibliogràfiques

Blanes, A. i Spijker, J. J. (2009) "Superervivència i patrons de la mortalitat de la població catalana, 1960-2007'. Treballs de la Societat Catalana de Geografia, núm. 69: pp. 67-95.

Cabré, A. (1999) El sistema català de reproducció. Barcelona, Proa.

Cabré, Anna i Domingo, Andreu (2014) "L'emigració des de Catalunya: aspectes demogràfics i prospectius". Sánchez-Montijano, E. i Alonso Calderón, X. (Eds.) L'emigració a Catalunya, Espanya i la Unió Europea. Barcelona: CIDOB-CEPAL, pp. 21-38.

Devolder, Daniel (2010) Anàlisi de la fecunditat a partir de l'Enquesta de mogràfica de 2007. Barcelona, Intitut d'Estadística de Catalunya, Generalitat de Catalunya.

Domingo, A. (2014) Catalunya al mirall migratori. Immigració $i$ identitat nacional. Barcelona, L'Avenç.

Esteve, Albert, Devolder, Daniel i Domingo, Andreu (2016) "Infecunditat a Espanya: tic, tac, tic, tac!" Perspectives Demogràfiques, 1, gener 2016, pp. 1-4.

Idescat (2014) Projeccions de población 2013-2051. Principals resultats. Barcelona: Institut d'Estadístia de Catalunya, Generalitat de Catalunya.

Solsona, M, Brullet, C i Spijker, J (2014) "Coparentalitat i custòdia compartida a Catalunya”. Documents d'Anàlisi Geogràfica, núm. 60:2, pp. 387-415

Una evolució sempre en els extrems, marcada pels alts i baixos del cicle econòmic. Cada cop més i amb massa freqüència, per a una part de la població, reeixir econòmicament i professional significa renunciar a tenir parella i/o fills, o marxar del país. Els canvis en els comportaments demogràfics poden ser entesos com estratègies resilients dels individus davant l'impacte de les transformacions econòmiques, que provoquen la intesificació del ritme estressat en termes de creixement poblacional. Però alhora, en conjunt les formes extremes en l'adaptació poden ser un signe de sobreescalfament del sistema.

Malgrat que en demografia l'estructura de la població per sexe i edat té una forta inèrcia sobre l'avenir a curt i mitjà termini -que fa preveure, per exemple, l'arribada de les generacions plenes del baby boom dels seixanta a l'edat de jubilació-, l'accidentada evolució de la població a Catalunya, depenent dels fluxos migratoris, ens obliga a la constant redefinició. Quan hem experimentat una acumulació de pertorbacions cada cop més intenses tot l'esforç ha d'anar dirigit a construir elements que possibilitin la cohesió social. A lluitar contra l'entropia que introdueix una economia de mercat que deixa les persones a la intempèrie i fa créixer la desigualtat. Catalunya, com a Sistema Complex de Reproducció basat en la immigració, està abocada a fer de l'excepcionalitat el seu tret característic, i a reformular-se dialècticament en la seva reincident trobada amb l'alteritat, fent de la immigració un dels seus mites fundacionals (Domingo, 2014). El futur, pendent de l'evolució de les migracions -és a dir, del cicle econòmic-, torna a ser una aposta contra la incertesa. Entremig d'aquesta acceleració vertiginosa, potser és el millor moment perquè ens preguntem cap a on anem, demogràficament parlant.

Consell de redacció

Andreu Domingo i Albert Esteve

Correspondència diriggida a:

Andreu Domingo

adomingo@ced.uab.cat

Crèdits

Revisió i comentaris: Amand Blanes, Anna Cabré, Albert Esteve, Jordi Bayona i Hermínia Pujol.

Edició de gràfics: Teresa Menacho.

Cita

Domingo, A. (2016) "Resiliència i estrès demogràtic a la Catalunya del segle XXI", Perspectives Demogràfiques, 2, 1-4.

Maquetació Ester Angulo.
Enllaç url

http://ced.uab.es/difusio/butlletiperspectives-demografiquesoo2

\section{Contacte}

Centre d'Estudis Demogràfics. Carrer de Ca n’Altayó, Edifici E2 Universitat Autònoma de Barcelona 08193 Bellaterra / Barcelona

Espanya

Telèfon: +34935813060 Mail: demog@ced.uab.cat Web: http://ced.uab.es/ 